\title{
STUDI SIFAT MEKANIK DAN STRUKTUR MIKRO PADA ALUMINIUM ALLOY 6061 DENGAN LAS TUNGSTEN INERT GAS UNTUK CHASIS GOKART
}

\author{
Christian Yoshua ${ }^{1 *}$, M. Sabri ${ }^{2}$, Farida Ariani ${ }^{3}$, Marragi M ${ }^{4}$, Syahrul Abda ${ }^{5}$ \\ ${ }_{1,2,3,4,5}$ Departemen Teknik Mesin, Fakultas Teknik, Universitas Sumatera Utara \\ Email: hutagaoljoshua25@gmail.com
}

\begin{abstract}
This research was carried out for the purpose of knowing the effect of the weld weld variations on Aluminum welding 6061 for kart chassis on impact strength, bending strength after welding and microstructure. Welding is done by the TIG welding method, using ER 5356 electrodes. The tools used in microstructure tests, impact tests and bending tests respectively are Metallurgycal Microscope, charpy tester and, three point bending. The results of the microstructure test show that it is thus due to the effect of heat during the welding process. This change in micro structure is caused by the influence of the incoming temperature during the welding process. Apart from the welding temperature, it is also influenced by the heat-treatment media used. For this test use air conditioning media. With the physical changes of Si granules into primary $\mathrm{Si}$ in the weld area it is also possible to change the mechanical properties of aluminum alloy 6061 for the kart chassis as a result of the impact test. thus causing the level of strength in the weld area to be denser with a single tapered seam and which is rarely found in a square seam (I closed). From the test results, the highest impact and energy values absorbed in square seam specimens (I closed) were obtained at 80 amperes for the kart chassis ie $\mathbf{E}=34.161$ Joules and $\mathbf{K}=0.341$ Joule $/ \mathrm{mm}^{2}$, the highest values were absorbed in Single V specimens obtained at 80 amperes for gokart chassis namely $\mathbf{E}=51.609$ Joules and $\mathbf{K}=0.516$ Joule $/ \mathrm{mm}^{2}$, then the highest value absorbed in Single Tire seam specimens was obtained at 80 amperes for kart chassis ie $\mathbf{E}=89.166$ Joule and $\mathbf{K}=0.891$ Joule $/ \mathrm{mm}^{2}$. From the test results, the highest bending and energy values absorbed in the square seam specimens (I closed) for the kart chassis are obtained at 80 amperes ie $\sigma=414,570 \mathrm{Mpa}$, then the highest value is absorbed on a single $\mathrm{V}$ specimen for the gokart chassis obtained at strong the 80 ampere current is $\boldsymbol{\sigma}=443.706 \mathrm{MPa}$, then the highest value absorbed in the Single Tire seam specimen for the kart chassis is obtained at 80 amperes of current ie $\sigma=570,353$.
\end{abstract}

Keywords: Welding TIG (Tungsten Inert Gas), Aluminium Alloy 6061, Chasis Gokart, Impact Test, Bending Test, Micro Structure, Variation of Hem.

\section{ABSTRAK}

Penelitian ini dilakukan untuk tujuan mengetahui pengaruh variasi kampuh las pada pengelasan Aluminium 6061 untuk chasis gokart terhadap kekuatan impak, kekuatan bending setelah dilakukan pengelasan dan struktur mikro. Pengelasan dilakukan dengan metode pengelasan TIG, menggunakan elektroda ER 5356. Alat yang digunakan dalam uji struktur mikro, uji impact dan uji bending secara berturut-turut adalah Metallurgycal Microscope, charpy tester dan, three point bending. Hasil dari uji struktur mikro menunjukkan bahwa dengan demikian akibat pengaruh panas pada saat proses pengelasan. Perubahan struktur mikro ini disebabkan oleh pengaruh suhu yang masuk pada saat proses pengelasan. Selain karena suhu pengelasan, juga dipengaruhi oleh media pendingin atau heat-treatment yang digunakan. Untuk pengujian ini menggunakan media pendingin udara. Dengan adanya perubahan fisik butiran Si menjadi Si primer pada daerah las tersebut juga dimungkinkan terjadi perubahan sifat mekanik pada aluminium alloy 6061 untuk chasis gokart sebagai mana pada hasil dari uji impact. dengan demikian menyebabkan tingkat kekuatan pada daerah las lebih rapat dengan kampuh tirus tunggal dan yang jarang kerapatannya di dapatkan dalam kampuh persegi (I tertutup). Dari hasil pengujian, nilai impak dan energy nilai yang tertinggi diserap pada spesimen kampuh persegi (I tertutup) diperoleh pada arus 80 ampere untuk chasis gokart yaitu $\mathbf{E}=34,161$ Joule dan $\mathbf{K}=0,341 \mathrm{Joule} / \mathrm{mm}^{2}$, nilai yang tertinggi diserap pada spesimen kampuh V Tunggal diperoleh pada arus 80 ampere untuk chasis gokart yaitu $\mathbf{E}=51,609$ Joule dan $\mathbf{K}=0,516 \mathrm{Joule} / \mathrm{mm}^{2}$, kemudian nilai yang tertinggi diserap pada spesimen kampuh Tirus Tunggal diperoleh pada arus 80 ampere untuk chasis gokart yaitu $\mathbf{E}=89,166$ Joule dan $\mathbf{K}=0,891 \mathrm{Joule} / \mathrm{mm}^{2}$. Dari hasil pengujian, nilai bending dan energi nilai yang tertinggi diserap pada spesimen kampuh persegi (I tertutup) untuk chasis gokart diperoleh pada arus 80 ampere yaitu $\boldsymbol{\sigma}=414,570 \mathrm{Mpa}$, kemudian nilai yang tertinggi diserap pada spesimen kampuh V Tunggal untuk chasis gokart diperoleh pada kuat arus 80 ampere yaitu $\quad \boldsymbol{\sigma}=443,706 \mathrm{Mpa}$, kemudian nilai yang tertinggi diserap pada spesimen kampuh Tirus Tunggal untuk chasis gokart diperoleh pada kuat arus 80 ampere yaitu $\boldsymbol{\sigma}=570,353$. 
Kata kunci: Pengelasan TIG (Tungsten Inert Gas), Aluminium Alloy 6061, Chasis Gokart, Pengujian Impact, Pengujian Bending, Struktur Mikro, Variasi Kampuh.

\section{Pendahuluan}

Pengelasan merupakan penyambungan dua bahan atau lebih yang didasarkan pada prinsip-prinsip proses difusi, sehingga terjadi penyatuan bagian bahan yang disambung. Kelebihan sambungan las adalah konstruksi ringan, dapat menahan kekuatan yang tinggi, mudah pelaksanaannya, serta cukup ekonomis namun kelemahan yang paling utama adalah terjadinya perubahan struktur mikro bahan yang di las sehingga terjadi perubahan sifat fisik maupun mekanis dari bahan yang di las. Dalam penelitian ini material yang disambung adalah aluminium. Ada beberapa macam jenis pengelasan yang sering digunakan untuk penyambungan aluminium diantaranya dengan menggunakan Las, salah satunya dengan metode las TIG ( Tungsten Inert Gas ) dan Oxy - acetylene. Kedua metode pengelasan tersebut dapat digunakan dalam pengelasan berbahan aluminium bila syarat dan metode terpenuhi (Wiryosumarto, $\mathrm{H}$. 2004).

Faktor yang memungkinkan mempengaruhi penurunan sifat mekanis sambungan las aluminium antara lain adalah ketidak sesuaian dalam pemilihan kawat las (fillermetal) dan kesalahan dalam penentuan parameter las TIG (Sulardjaka, 2005).

Untuk mendapatkan hasil sambungan las aluminium yang bagus perlu diperhatikan faktor faktor penting antara lain :

1. Preparasi lasannya (before welding), terutama pembersihan permukaan aluminium yang akan di las.

2. Masukan panas (heat input) tertentu dan faktor parameter ini dipengaruhi oleh arus, tegangan dan kecepatan las. Juga jenis nyala api untuk pengelasan dengan proses $O x y$ acetylene.

3. Pemilihan kawat las (filler metal) yang sesuai kecepatan pengelasan.

4. Penentuan jenis sambungan las (Sulardjaka, 2005)

Untuk mengetahui sifat mekanik variasi kampuh pada pengujian impact, uji bending dan Struktur Mikro pengelasan TIG (Tungsten Innert Gas) pada material Aluminium alloy 6061 untuk chasis gokart yang menghasilkan sifat mekanik yang paling baik, perlu dilakukan penelitian dan pengujian. Salah satu sifat mekanik yang paling penting dalam pengelasan adalah sifat ketangguhan impact, dan pengujian bending alumunium alloy 6061 .

\section{Metode}

Penelitian ini dilakukan dilaboratorium Pengujian Departmen Teknik Mesin Universitas Sumatera Utara dan laboratorium Impact dan fracture S2 Universitas Sumatera Utara. Penelitian ini dilaksanakan mulai bulan november 2018 sampai dengan bulan februari 2019. Dalam melakukan penelitian tugas akhir ini penulis melakukan pengujian dilaboratorium Pengujian Departmen Teknik Mesin Universitas Sumatera Utara dan laboratorium Impact dan fracture S2 Universitas Sumatera Utara.

Proses pengujian dilaksanakan terhadap pengelasan aluminium 6061 pada sambungan pengelasan dengan variasi kampuh dengan Las tungsten inert gas yang ditinjau dari uji mekanis meliputi uji impak daerah Las, uji bending dan struktur mikro.

Teknik pengumpulan data yang diperoleh dari proses pengelasan yang dilakukan dari hasil pengujian impak, uji bending dan struktur mikro pada masing masing allumunium yg di las sebanyak 18 spesimen 9 spesimen uji impact, dimana 3 spesimen setelah dilakukan pengelasan dengan variasi kampuh $\mathrm{V}$ tunggal, 3 spesimen setelah dilakukan pengelasan dengan variasi kampuh persegi, 3 spesimen setelah dilakukan pengelasan dengan variasi kampuh tirus tunggal, dan 9 spesimen uji bending, dimana 3 spesimen setelah dilakukan pengelasan dengan 
variasi kampuh $\mathrm{V}$ tunggal, 3 spesimen setelah dilakukan pengelasan dengan variasi kampuh persegi, 3 spesimen setelah dilakukan pengelasan dengan variasi kampuh tirus tunggal. dari hasil impact di lakukan struktur mikro setelah di lakukan pengelasan.

Metode analisa dan evaluasi data yang diperoleh dari pengujian yang dilakukan di laboratorium pada masing-masing spesimen adalah kualitatif. Dari data inilah akan dicari hasil untuk uji impak, uji bending pada daerah Las, dan struktur mikro pengelasan TIG (Tungsten Inert Gas).

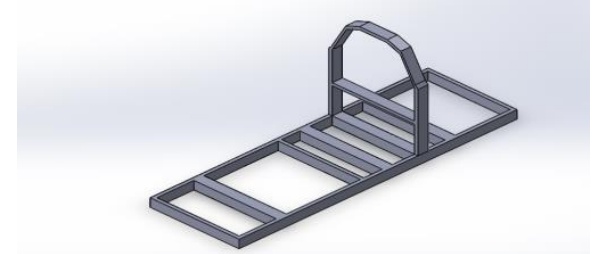

Gambar 2.1 Chasis Gokart

\subsection{Pengujian Impact}

Metode uji charpy lazim digunakan di Inggris dan Eropa, Benda uji charpy mempunyai penampang lintang bujur sangkar atau lingkaran dengan takik V di dekat ujung yang dijepit, kemudian uji impak dengan metode ini umumnya juga dilakukan hanya pada temperatur ruang dan ditujukan untuk material-material yang didisain untuk berfungsi sebagai cantilever,

Perbedaan mendasar charpy dengan izod adalah peletakan spesimen. Pengujian dengan menggunkan izod tidak seakurat pada pengujian charpy, karena pada izod pemegang spesimen juga turut menyerap energi, sehingga energi yang terukur bukanlah energi yang mampu di serap material seutuhnya.

Berikut ini adalah prosedur percobaan yang dilakukan pada pengujian Impact dengan metode Charpy :

1. Menyiapkan alat dan bahan.

2. Mengukur specimen untuk t1,t2, P, L, kedalaman.

3. Mengukur luas specimen yang akan diujikan.

4. Memasang spesimen pada penahan pada impak tester, setelah mengkalibrasi impak tester.

5. Mengangkat pendulum dan melepaskan tuas.

6. Melakukan analisa.

Untuk mencari energi yang dibutuhkan untuk mematahkan sampel (energi yang diserap) dinyatakan dalam persamaan:

$$
\mathrm{E} \quad=\text { P.D }(\cos \beta-\cos \alpha)
$$

Keterangan:

$\mathrm{E} \quad=$ Energi yang dibutuhkan untuk mematahkan sampel (Joule)

$\mathrm{P}=$ Berat Palu $\mathrm{x}$ gravitasi yaitu 251,3N

$\mathrm{D}=$ Jarak lengan pengayun yaitu $0,6495 \mathrm{~m}$

$\operatorname{Cos} \beta=$ Sudut akhir pemukulan

$\operatorname{Cos} \alpha=$ Sudut awal pemukulan yaitu konstan $147^{\circ}$

Sedangkan untuk mendapatkan nilai impak maka dapat dihitung menggunakan persamaan:

$\mathrm{K}_{\mathrm{i}}=\mathrm{E} / \mathrm{A}_{\mathrm{i}}$ 


\author{
Keterangan: \\ $\mathrm{K}_{\mathrm{i}}=$ Nilai impak $\left(\mathrm{Joule} / \mathrm{mm}^{2}\right)$ \\ $\mathrm{E}=$ Energi yang dibutuhkan untuk mematahkan sampel (Joule) \\ $\mathrm{A}_{\mathrm{i}}=$ Luas penampang sampel $\left(\mathrm{mm}^{2}\right)$
}

\title{
2.2 PengujianLengkung (Bending)
}

Pengujian bending merupakan salah satu pengujian sifat mekanik bahan yang dilakukan terhadap specimen dari bahan baik bahan yang akan digunakan sebagai konstruksi atau komponen yang akan menerima pembebanan. Dengan pembebanan ini bahkan akan mengalami deformasi dengan dua buah gaya yan berlawanan bekerja saat yang bersamaan. Be berdasarkan kepada kebutuhan tersebut makan pengujian lengkung dibedakan menjadi 2, yaitu:

a. Pengujian lengkung beban dan

b. Pengujian lengkung perubahan bentuk.

Pengujian lengkung beban ialah pengujian lengkung yang bertujuan untuk mengetahui aspek-aspek kemampuan bahan uji dalam dalam menerima pembebanan lengung, yakni :

a. Kekuatan atau tegangan lengkung

b. Lenturan atau defleksi (f) Sudut yang terbentuk oleh lenturan atau sudut defleksi.

c. Elastisitas (E)

Terdapat dua macam tipe pengujian bending, pengujian bending tiga titik dan pengujian bending empat titik. Konfigurasi uji bending tiga titik dimana serat penyusun komposit tegak lurus dengan panjang spesimen disebut uji bending melintang (transverse bend test). Terdapat dua kemungkinan penyusunan serat, yaitu dengan serat sejajar dengan panjang spesimen dan serat melintang terhadap panjang spesimen. Berikut ini adalah gambar three point bending.
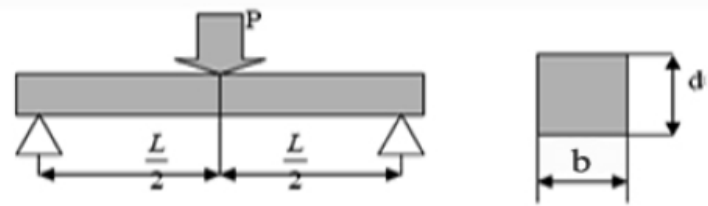

Gambar 2.2 Three Point Bending

Persamaan pada pengujian bending adalah sebagai berikut :

Keterangan :

$$
\sigma=\frac{3 x F m a x \times L}{2 t^{2} \times W} M P a
$$

$\sigma \quad=$ Kekuatan Bending $\left(\mathrm{N} / \mathrm{mm}^{2}\right)$

Fmax = Beban $(\mathrm{N})$

$\mathrm{L} \quad=$ Jarak antar tumpuan $(\mathrm{mm})$

$\mathrm{t} \quad=$ Tebal spesimen $(\mathrm{mm})$

$\mathrm{W}=$ Lebar spesimen $(\mathrm{mm})$ 


\subsection{Struktur Mikro}

Struktur mikro adalah gambaran dari kumpulan fasa-fasa yang dapat diamati melalui teknik metalografi. Struktur mikro suatu logam dapat dilihat dengan menggunakan mikroskop. Mikroskop yang dapat digunakan yaitu mikoroskop optik dan mikroskop elektron. Sebelum dilihat dengan mikroskop, permukaan logam harus dibersihkan terlebih dahulu, kemudian reaksikan dengan reagen kimia untuk mempermudah pengamatan. Proses ini dinamakan etching. (Wiryosumarto, 2000).

Untuk mengetahui sifat dari suatu logam, kita dapat melihat struktur mikronya. Setiap logam dengan jenis berbeda memiliki struktur mikro yang berbeda. Dengan melalui diagram fasa, kita dapat meramalkan struktur mikronya dan dapat mengetahui fasa yang akan diperoleh pada komposisi dan temperatur tertentu. Dan dari struktur mikro kita dapat melihat:

a. Ukuran dan bentuk butir

b. Distribusi fasa yang terdapat dalam material khususnya logam

c. Pengotor yang terdapat dalam material

Dari struktur mikro kita juga dapat memprediksi sifat mekanik dari suatu material sesuai dengan yang kita inginkan.

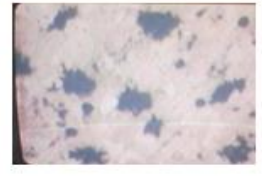

Besi cor malleable

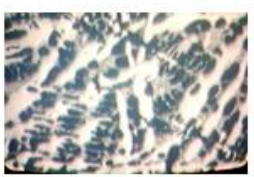

Besi cor putih

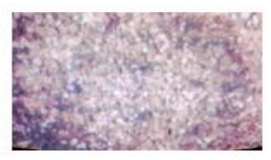

Baja karbon rendah

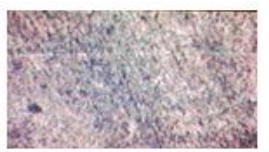

Baja coating $\mathrm{Zn}_{\mathrm{n}}$

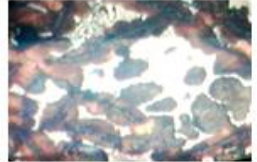

Besi cor kelabu

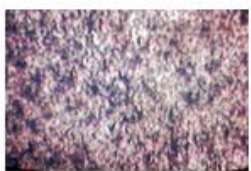

Struktur lasan

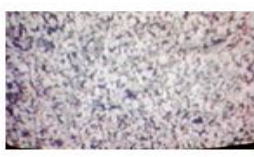

Baja karbon medium

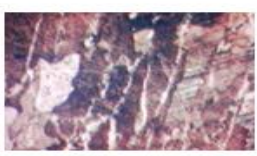

Aluminium 2024

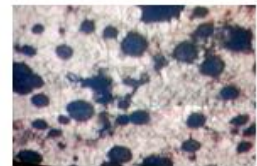

Besi cor nodular

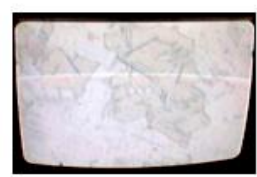

Baja tahan karat austenitik

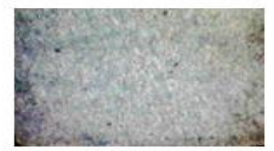

Baja karbon tinggi

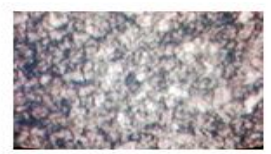

Aluminium $6 \times x \times$ ekstrusi

Gambar 2.3 Struktur Mikro pada Logam (Wiryosumarto, 2000)

\section{Analisia dan Pembahasan}

3.1Hasil Uji Impak Las TIG 80 Ampere Variasi Kampuh Untuk Chasis Gokart

Pengujian impak bertujuan untuk mengukur berapa energi yang dapat diserap suatu material sampai material tersebut patah. Pengujian impact merupakan respon terhadap beban kejut atau beban tiba-tiba (beban impak) (Halimatuddahliana dkk, 2016). Pengujian impak dilakukan pada sampel uji menggunakan metode charpy.

Untuk mencari energi yang dibutuhkan untuk mematahkan sampel (energi yang diserap) di hitung menggunakan persamaan $\mathbf{2 . 1}$

$$
\mathrm{E}=\mathrm{P} . \mathrm{D}(\cos \beta-\cos \alpha)
$$




$$
\begin{aligned}
E & =P \times D\left(\cos 125^{\circ}-\cos 147^{\circ}\right) \\
& =163,219 \times 0,6495(-0,5735-(-0,8386)) \\
& =163,219(0,2651) \\
& =43,269 \text { Joule }
\end{aligned}
$$

Sedangkan untuk mendapatkan nilai impak maka dapat dihitung menggunakan persamaan: $\mathbf{2 . 2}$

$$
\begin{aligned}
\mathrm{K}_{\mathrm{i}} & =43,269 / 100 \\
& =0,432 \text { Joule } / \mathrm{mm}^{2}
\end{aligned}
$$

Keterangan :

$\mathrm{E} \quad=$ Energi yang dibutuhkan untuk mematahkan sampel (Joule)

$\mathrm{P}=$ Berat Palu $\mathrm{x}$ gravitasi yaitu 251,3N

$\mathrm{D} \quad=$ Jarak lengan pengayun yaitu $0,6495 \mathrm{~m}$

$\operatorname{Cos} \beta=$ Sudut akhir pemukulan

$\operatorname{Cos} \alpha=$ Sudut awal pemukulan yaitu konstan $147^{\circ}$

\begin{tabular}{|c|c|c|c|c|c|}
\hline \multirow{2}{*}{ KAMPUH } & \multirow{2}{*}{$\begin{array}{c}\text { SPESIMEN } \\
\text { NO. }\end{array}$} & \multicolumn{4}{|c|}{ DATA UJI IMPACT } \\
\hline & & $\operatorname{Cos} \alpha$ & $\operatorname{Cos} \beta$ & E (Joule) & K (Joule/ $\mathbf{m m}^{2}$ ) \\
\hline \multirow{4}{*}{$\begin{array}{l}\text { PERSEGI } \\
\text { (I } \\
\text { TERTUTUP) }\end{array}$} & 1 & $147^{\circ}$ & $131^{\circ}$ & 29,803 & 0,298 \\
\hline & 2 & $147^{\circ}$ & $130^{\circ}$ & 31,974 & 0,319 \\
\hline & 3 & $147^{\circ}$ & $129^{\circ}$ & 34,161 & 0,341 \\
\hline & Rata-rata & $147^{\circ}$ & & 31,979 & 0,319 \\
\hline \multirow{4}{*}{ V TUNGGAL } & 1 & $147^{\circ}$ & $125^{\circ}$ & 43,269 & 0,432 \\
\hline & 2 & $147^{\circ}$ & $124^{\circ}$ & 45,619 & 0,456 \\
\hline & 3 & $147^{\circ}$ & $121,5^{\circ}$ & 51,609 & 0,516 \\
\hline & Rata-rata & $147^{\circ}$ & & 46,832 & 0,468 \\
\hline \multirow{4}{*}{$\begin{array}{c}\text { TIRUS } \\
\text { TUNGGAL }\end{array}$} & 1 & $147^{\circ}$ & $111^{\circ}$ & 78,394 & 0,783 \\
\hline & 2 & $147^{\circ}$ & $109^{\circ}$ & 83,747 & 0,837 \\
\hline & 3 & $147^{\circ}$ & $107^{\circ}$ & 89,166 & 0,891 \\
\hline & Rata-rata & $147^{\circ}$ & & 83,769 & 0,837 \\
\hline
\end{tabular}

Hasil perhitungan energi yang diserap untuk mematahkan spesimen dan nilai impak untuk spesimen pada daerah las untuk chasis mobil gokart, berikutnya analog untuk perhitungan di atas. Hasil perhitungan ditampilkan dalam tabel 3.1 berikut ini:

Tabel 3.1 Data Hasil perhitungan Uji Impact Aluminium Alloy Untuk chasis Gokart 6601 variasi kampuh pada pengelasan TIG 80 Ampere Dalam Bentuk Tabel.

Dari tabel diatas menunjukkan untuk kuat arus 80 ampere pada kampuh persegi / I tertutup terhadap energi yang diserap untuk chasis gokart dan nilai impak dari Aluminium Alloy 6061 tersebut, Dari gambar terlihat bahwa spesimen mendapatkan rata - rata sekitar 0,319 Joule/ $\mathrm{mm}^{2}$, dan dari tabel diatas menunjukkan untuk kampuh $\mathrm{V}$ tunggal kuat arus 80 ampere untuk chasis gokart terhadap energi yang diserap dan nilai impak dari Aluminium Alloy 6601 
tersebut, Dari gambar terlihat bahwa spesimen mendapatkan rata - rata sekitar 0,468 Joule/ $\mathrm{mm}^{2}$, dan dari tabel diatas menunjukkan untuk kuat arus 80 ampere pada kampuh Tirus Tunggal untuk chasis gokart terhadap energi yang diserap dan nilai impak dari Aluminium Alloy 6601 tersebut, Dari gambar terlihat bahwa spesimen mendapatkan rata - rata sekitar 0,837 Joule/ $\mathrm{mm}^{2}$.

Dari hasil pengujian, nilai impak dan energy nilai yang tertinggi diserap pada spesimen kampuh persegi (I tertutup) diperoleh pada arus 80 ampere untuk chasis gokart yaitu $\mathbf{E}=$ 34,161 Joule dan $\mathbf{K}=0,341$ Joule $/ \mathrm{mm}^{2}$, nilai yang tertinggi diserap pada spesicmen kampuh $\mathrm{V}$ Tunggal diperoleh pada arus 80 ampere untuk chasis gokart yaitu $\mathbf{E}=51,609$ Joule dan $\mathbf{K}=$ 0,516 Joule $/ \mathrm{mm}^{2}$, kemudian nilai yang tertinggi diserap pada spesimen kampuh Tirus Tunggal diperoleh pada arus 80 ampere untuk chasis gokart yaitu $\mathbf{E}=89,166$ Joule dan $\mathbf{K}=0,891$ Joule $/ \mathrm{mm}^{2}$.

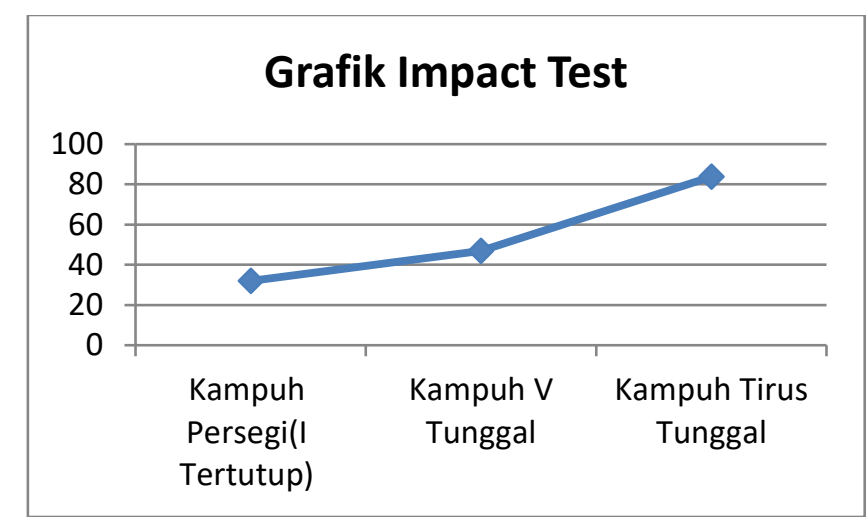

Gambar 3.1 Grafik Energi Yang Diserap Pada Daerah Las Terhadap Variasi Kampuh Untuk Chasis Gokart

3.2 Hasil Patahan Pada Spesimen Uji Impact Variasi Kampuh 80 Ampere Untuk Chasis Gokart

a. Spesimen kampuh persegi (I tertutup) 80 Ampere

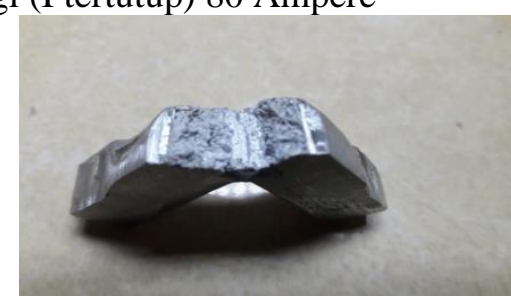

Gambar 3.2 Spesimen UJi Impact Dengan Kampuh I Tertutup Arus 80 Ampere

Dengan demikian memperlihatkan jenis patahan impact dengan nilai tertinggi $\mathbf{K}=$ $0,341 \mathrm{Joule} / \mathrm{mm}^{2}$. Hasil patahan memperlihatkan permukaan patahan yang datar yang mampu memberikan daya pantul cahaya yang tinggi (mengkilat). Dilihat dari rambatan, struktur permukaan dan nilai impak yang didapat maka jenis patahan yang dialami spesimen akibat beban kejut yang diberikan adalah jenis patahan getas. 
b. Spesimen kampuh V Tunggal 80 Ampere

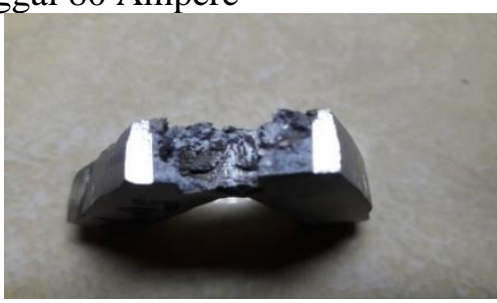

Gambar 3.3 Spesimen UJi Impact Kampuh V Tunggal Arus 80 Ampere

Dengan demikian Memperlihatkan jenis patahan impact dengan nilai tertinggi $\mathbf{K}=$ $0,516 \mathrm{Joule} / \mathrm{mm}^{2}$. Hasil patahan memperlihatkan permukaan patahan yang tidak datar dan berserat yang berbentuk dimpel yang menyerap cahaya dan berpenampilan buram. Dilihat dari rambatan, struktur permukaan dan nilai impak yang didapat maka jenis patahan yang dialami spesimen akibat beban kejut yang diberikan adalah jenis patahan campuran yaitu patahan yang terjadi pada bahan yang cukup kuat namun ulet.

c. Spesimen kampuh Tirus Tunggal 80 Ampere

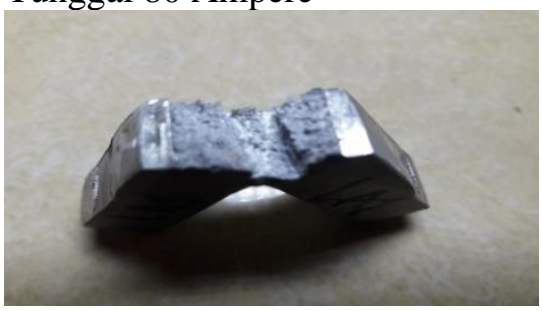

Gambar 3.4 Spesimen UJi Impact Kampuh Tirus Tunggal Arus 80 Ampere

Dengan demikian memperlihatkan jenis patahan impact dengan nilai tertinggi $\quad \mathbf{K}=89,166$ Joule $/ \mathrm{mm}^{2}$. Hasil patahan memperlihatkan permukaan patahan yang tidak datar dan berserat yang berbentuk dimpel yang menyerap cahaya dan berpenampilan buram. Dilihat dari rambatan, struktur permukaan dan nilai impak yang didapat maka jenis patahan yang dialami spesimen akibat beban kejut yang diberikan adalah jenis patahan campuran yaitu patahan yang terjadi pada bahan yang cukup kuat namun ulet.

\subsection{Hasil Pengujian Lengkung (Bending)}

Pengujian ini merupakan salah satu pengujian sifat mekanik bahan yang digunakan untuk mengukur kekuatan material akibat pembebanan. Pengujian Bending dilakukan pada semua spesimen dengan standart ASTM E 290-14, dimana bentuk spesimen yang digunakan berbentuk strip dengan ukuran, $\mathrm{p}=10 \mathrm{~mm} \mathrm{l}=25 \mathrm{~mm}$ dan $\mathrm{t}=3 \mathrm{~mm}$.

Sedangkan pengujian bending ini dilakukan berdasarkan standard pengujian ASTM D 790. Pengujian ini dilakukan terhadap spesimen alumunium 6061 untuk chasis gokart menggunakan metode pengujian three point bending dengan beban uji 1000kg jarak tumpuan spesimen $50 \mathrm{~mm}$ dan cross head speed $10 \mathrm{~mm} / \mathrm{menit}$ Foto pengujian bending dapat dilihat pada gambar 4.5

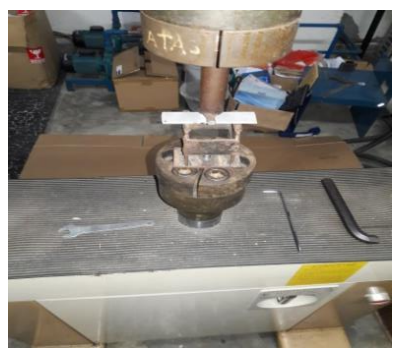

Gambar 3.5 Pengujian Uji Lengkung (Bending) Untuk Chasis Gokart 
Hasil pengujian Bending dapat dihiung dengan menggunakan persamaan 2.3:

Keterangan :

$$
\sigma=\frac{3 \times \text { Fmax x L }}{2 \mathrm{t}^{2} \times \mathrm{W}} \mathrm{MPa}
$$

$$
\begin{array}{ll}
\sigma & =\operatorname{Kekuatan} \text { Bending }\left(\mathrm{N} / \mathrm{mm}^{2}\right) \\
\mathrm{Fmax} & =\text { Beban }(\mathrm{N}) \\
\mathrm{L} & =\operatorname{Jarak} \text { antar tumpuan }(\mathrm{mm}) \\
\mathrm{T} & =\text { Tebal spesimen }(\mathrm{mm}) \\
\mathrm{W} & =\text { Lebar spesimen }(\mathrm{mm})
\end{array}
$$

\begin{tabular}{|c|c|c|c|c|c|c|}
\hline \multirow[b]{2}{*}{ KAMPUH } & \multirow[b]{2}{*}{$\begin{array}{c}\text { SPESIMEN } \\
\text { No. }\end{array}$} & \multicolumn{3}{|c|}{ UKURAN BENDA UJI ( SPESIIEN) } & \multirow[b]{2}{*}{$\begin{array}{c}\text { Fmax } \\
\text { (kgf) }\end{array}$} & \multirow{2}{*}{$\begin{array}{c}\sigma \\
\text { (Mpa) }\end{array}$} \\
\hline & & $\begin{array}{c}\mathbf{P} \\
(\mathbf{m m})\end{array}$ & $\underset{(\mathrm{mm})}{\mathbf{W}}$ & $\underset{(\mathbf{m m})}{\mathbf{T}}$ & & \\
\hline \multirow{4}{*}{$\begin{array}{c}\text { PERSEGI } \\
\text { (I TERTUTUP) }\end{array}$} & 1 & 10 & 25 & 3 & 24,53 & 240,639 \\
\hline & 2 & 10 & 25 & 3 & 40,53 & 397,599 \\
\hline & 3 & 10 & 25 & 3 & 42,26 & 414,570 \\
\hline & Rata-rata & & & & 35,773 & 350,936 \\
\hline \multirow{4}{*}{ V TUNGGAL } & 1 & 10 & 25 & 3 & 44,42 & 435,760 \\
\hline & 2 & 10 & 25 & 3 & 44,61 & 437,624 \\
\hline & 3 & 10 & 25 & 3 & 45,23 & 443,706 \\
\hline & Rata-rata & & & & 44,753 & 439,03 \\
\hline \multirow{4}{*}{$\begin{array}{c}\text { TIRUS } \\
\text { TUNGGAL }\end{array}$} & 1 & 10 & 25 & 3 & 54,80 & 537,588 \\
\hline & 2 & 10 & 25 & 3 & 55,73 & 546,711 \\
\hline & 3 & 10 & 25 & 3 & 58,14 & 570,353 \\
\hline & Rata-rata & & & & 56,223 & 551,550 \\
\hline
\end{tabular}

Tabel 3.2 Data Hasil Perhitungan Uji Lengkung (Bending) Aluminium Alloy 6601 Variasi Kampuh Untuk Chasis Gokart Pada Pengelasan TIG 80 Ampere Dalam Bentuk Tabel.

Dari tabel diatas menunjukkan dengan arus 80 ampere pada kampuh persegi / I tertutup terhadap energi yang diserap dan nilai bending dari Aluminium Alloy 6601 untuk chasis gokart tersebut, Dari gambar terlihat bahwa spesimen mendapatkan rata - rata sekitar 350,936 Mpa, dan dari tabel diatas menunjukkan untuk kampuh $\mathrm{V}$ tunggal dengan arus 80 ampere terhadap energi yang diserap dan nilai bending dari Aluminium Alloy 6601 untuk chasis gokart tersebut, dari gambar terlihat bahwa spesimen mendapatkan rata-rata sekitar 439,03 Mpa, dan dari tabel diatas menunjukkan untuk arus 80 ampere pada kampuh Tirus Tunggal terhadap energi yang diserap dan nilai Bending dari Aluminium Alloy 6601 untuk chasis gokart tersebut, Dari gambar terlihat bahwa spesimen mendapatkan rata - rata sekitar 551,550 Mpa.

Dari hasil pengujian, nilai bending dan energi nilai yang tertinggi diserap pada spesimen kampuh persegi (I tertutup) untuk chasis gokart diperoleh pada arus 80 ampere yaitu $\boldsymbol{\sigma}=414,570 \mathrm{Mpa}$, kemudian nilai yang tertinggi diserap pada spesimen kampuh V Tunggal untuk chasis gokart diperoleh pada kuat arus 80 ampere yaitu $\quad \boldsymbol{\sigma}=443,706 \mathrm{Mpa}$, kemudian nilai yang tertinggi diserap pada spesimen kampuh Tirus Tunggal untuk chasis gokart diperoleh pada kuat arus 80 ampere yaitu $\boldsymbol{\sigma}=570,353$

\section{Grafik Pengujian Lengkung (Bending) Kampuh Persegi (I Tertutup)}

a. Grafik spesimen 1 


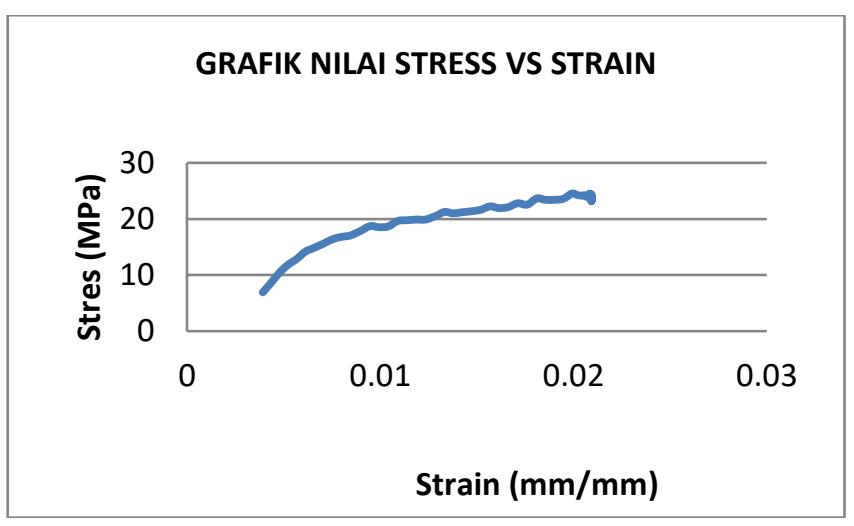

Gambar 3.6 Grafik Pengujian Lengkung (Bending) Kampuh Persegi (I Tertutup) Spesimen 1

b. Grafik spesimen 2

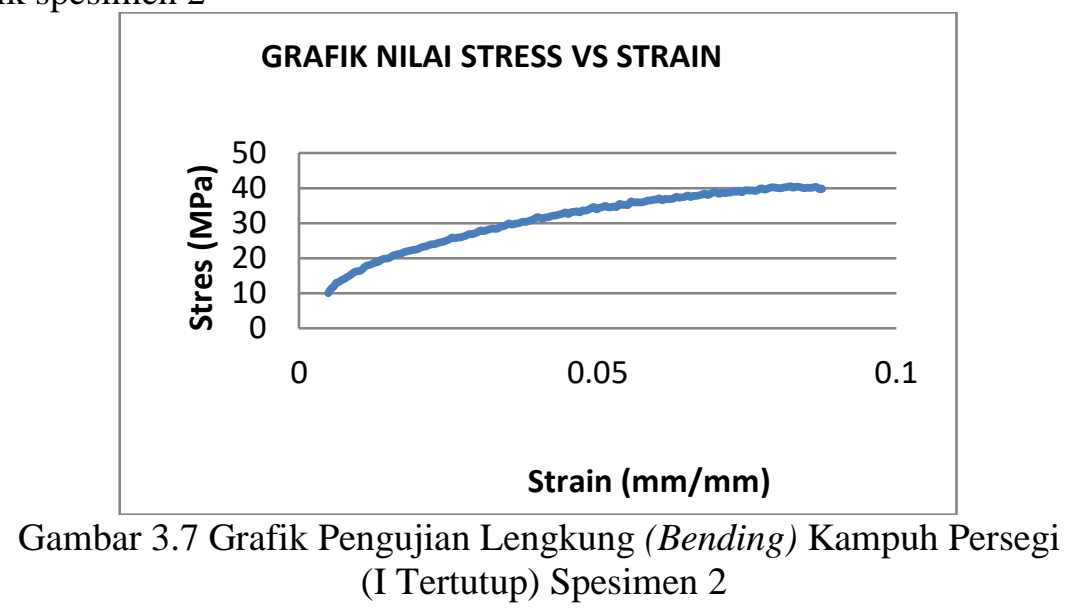

c. Grafik spesimen 3

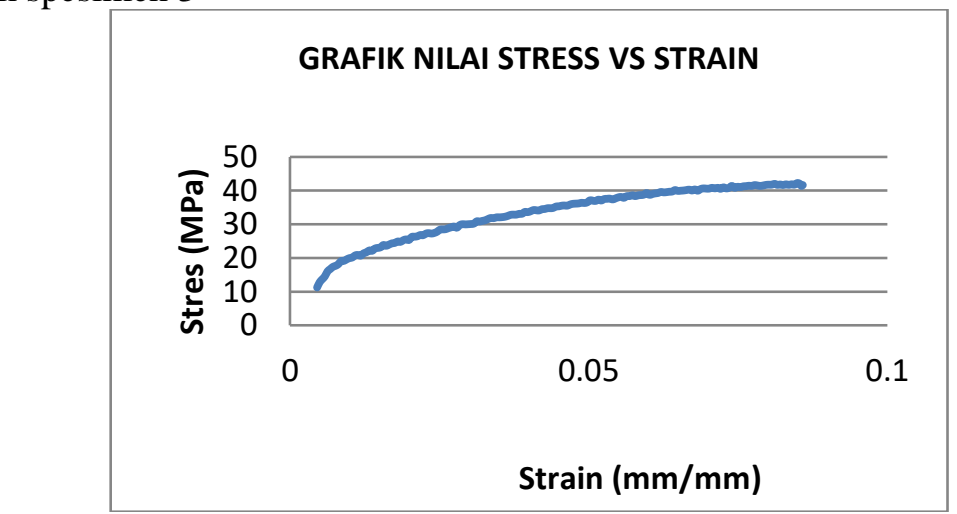

Gambar 3.8 Grafik Pengujian Lengkung (Bending) Kampuh Persegi

(I Tertutup) Spesimen 3

2. Grafik Pengujian Lengkung (Bending) Kampuh V Tunggal

a. Grafik spesimen 1 


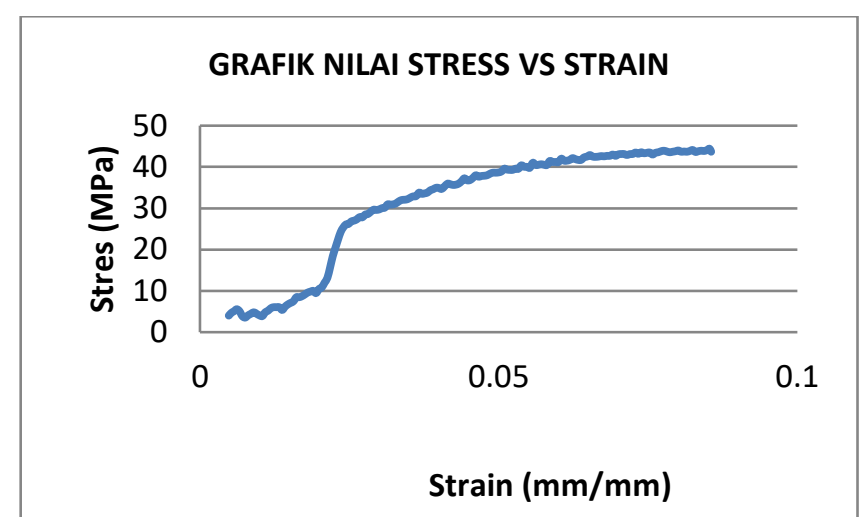

Gambar 3.9 Grafik Pengujian Lengkung (Bending) Kampuh V Tunggal Spesimen 1

b. Grafik spesimen 2

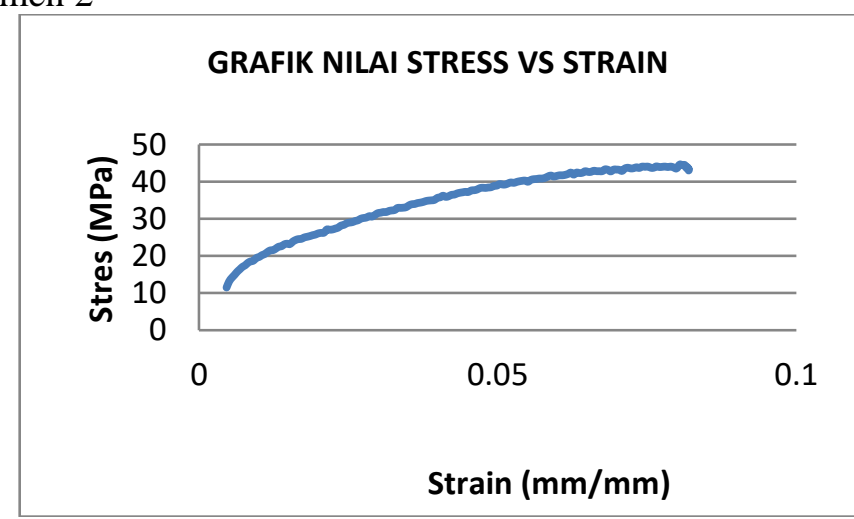

Gambar 3.10 Grafik Pengujian Lengkung (Bending)

Kampuh V Tunggal Spesimen 2

c. Grafik spesimen 3

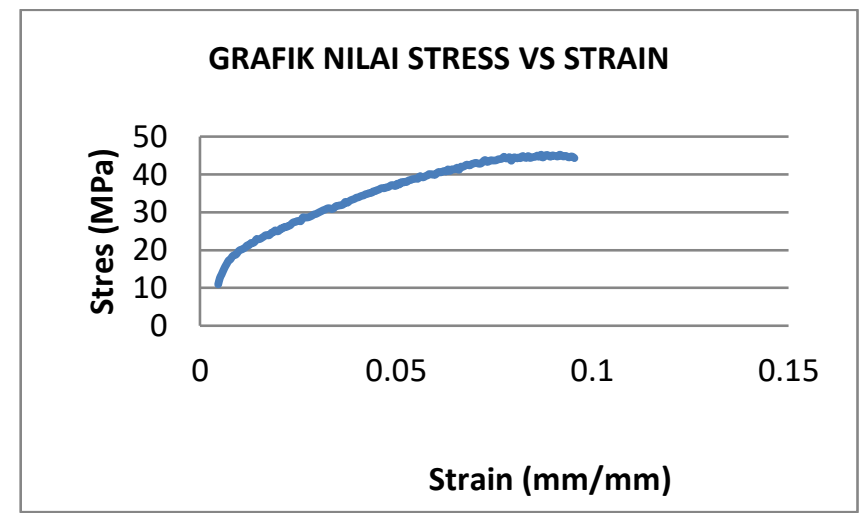

Gambar 3.11 Grafik Pengujian Lengkung (Bending) Kampuh V Tunggal Spesimen 3

3. Grafik pengujian lengkung (bending) kampuh Tirus Tunggal

a. Grafik spesimen 1 


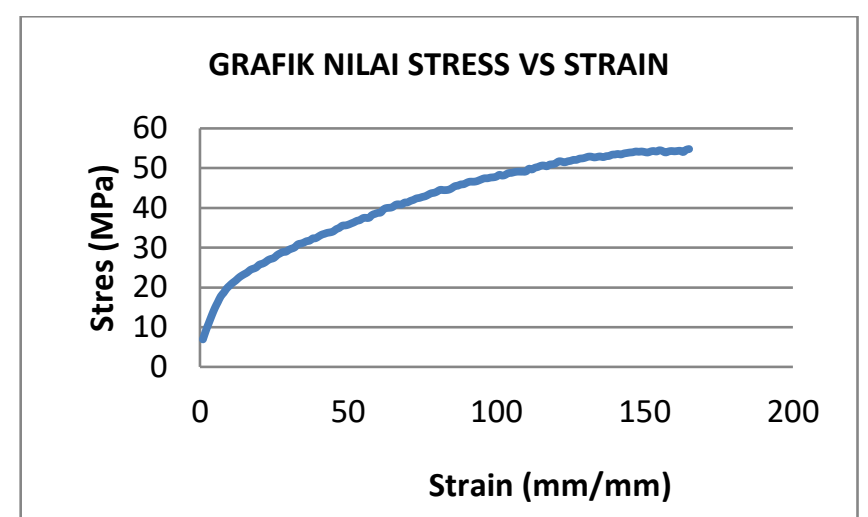

Gambar 3.12 Grafik Pengujian Lengkung (Bending) Kampuh Tirus Tunggal Spesimen 1

b. Grafik spesimen 2

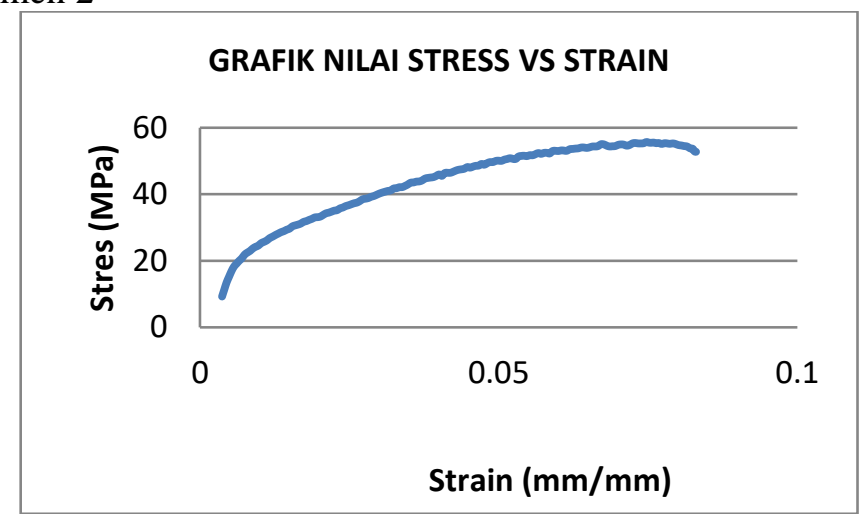

Gambar 3.13 Grafik Pengujian Lengkung (Bending) Kampuh Tirus Tunggal Spesimen 2

c. Grafik spesimen 3

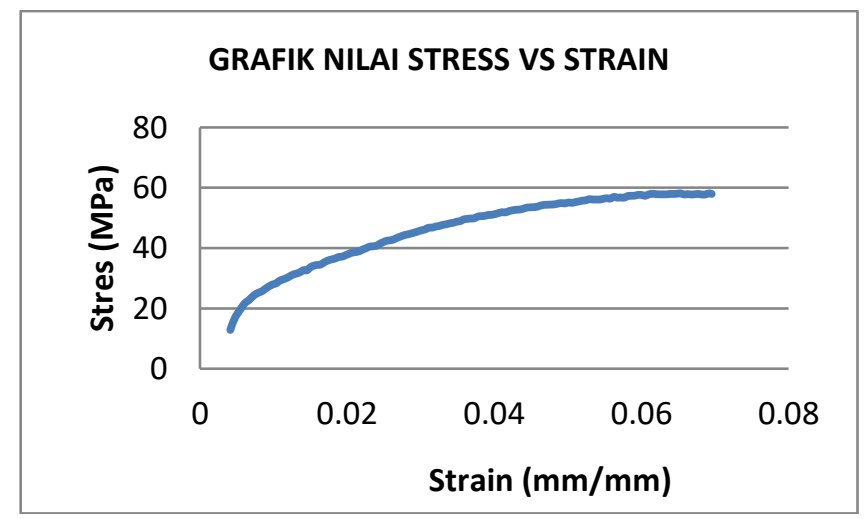

Gambar 3.14 Grafik Pengujian Lengkung (Bending) Kampuh Tirus Tunggal Spesimen 3

\subsection{Hasil Metalographi}

Struktur mikro adalah gambaran dari kumpulan fasa-fasa yang dapat diamati melalui teknik metalografi. Struktur mikro suatu logam dapat dilihat dengan menggunakan mikroskop. Mikroskop yang dapat digunakan yaitu mikoroskop optik dan mikroskop elektron. Sebelum dilihat dengan mikroskop, permukaan logam harus dibersihkan terlebih dahulu, kemudian reaksikan dengan reagen kimia untuk mempermudah pengamatan. Proses ini dinamakan etching. (Wiryosumarto, 2000).

Pengujian mikrostruktur dilakukan dengan menggunakan "Reflected Metallurgical Microscope" dengan type Rax Vision No.545491, MM -10A,230V-50Hz. Pengujian 
mikrostruktur ini dilakukan pada spesimen alumunium alloy 6061 yang telah dilakukan pengelasan dengan variasi kampuh persegi, kampuh $\mathrm{V}$ tunggal, dan kampuh tirus tunggal serta kuat arus 80 A untuk chasis gokart.

Pada pengujian struktur mikro, pengamatan dilakukan pada spesimen dengan mikroskop optik setelah spesimen uji dietsa dengan 2,5\% HNO3 dengan perbesaran 100x pada permukaan aluminium alloy 6061 .

Hasil foto mikro seperti diperlihatkan pada gambar-gambar berikut:

a. Hasil Uji Metalographi kampuh persegi (I Tertutup)

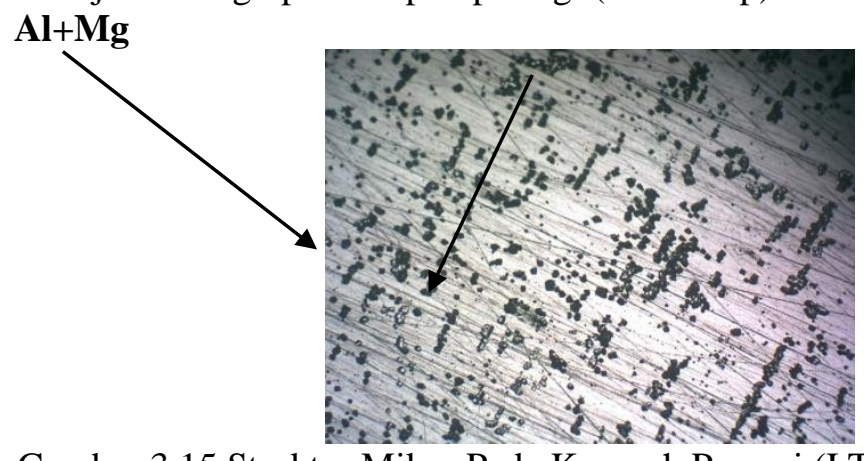

Gambar 3.15 Struktur Mikro Pada Kampuh Persegi (I Tertutup) Arus 80 A

b. Hasil Uji Metalographi Kampuh V Tunggal
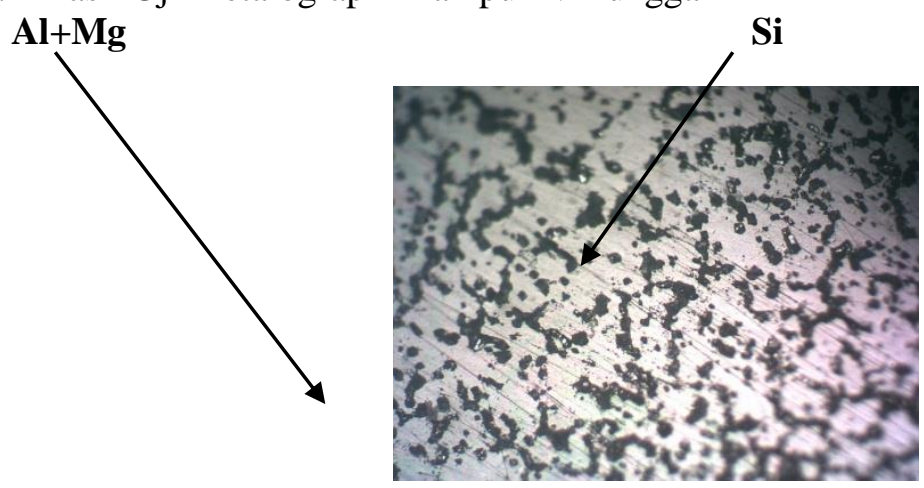

Gambar 3.16 Struktur Mikro Pada Kampuh V Tunggal Arus 80 A

c. Hasil Uji Metalographi Kampuh Tirus Tunggal

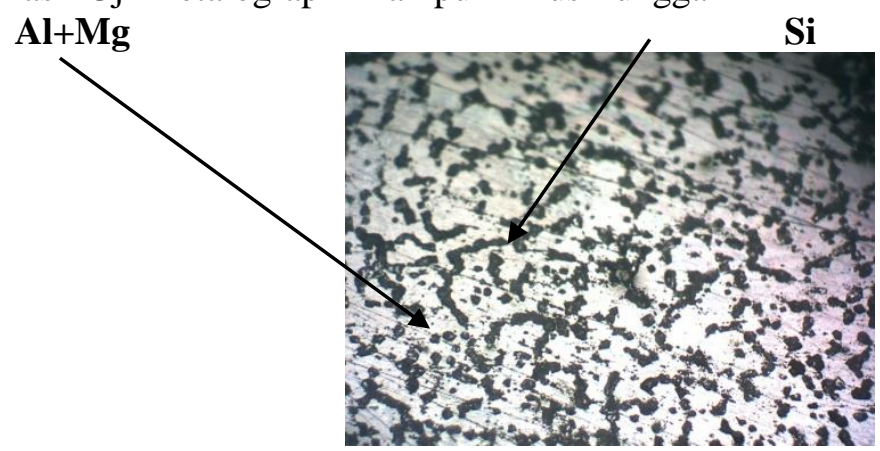

Gambar 3.17 Struktur Mikro Pada Kampuh Tirus Tunggal Arus 80 A

Pada daerah las sebagai mana pada gambar 3.15 magnesium dan aluminium pada daerah las terlihat mengkilap dengan strukturnya lebih rapat.

Gambar 3.16 menunjukkan adanya struktur paduan Si primer diantara aluminium primer. Hal tersebut dimungkinkan karena terjadinya difusi unsur $\mathrm{Al}$ dan $\mathrm{Si}$

Pada daerah las sebagai mana pada gambar 3.17 magnesium dan aluminium pada daerah las terlihat mengkilap dengan strukturnya lebih rapat.

Dengan demikian akibat pengaruh panas pada saat proses pengelasan. Perubahan struktur mikro ini disebabkan oleh pengaruh suhu yang masuk pada saat proses pengelasan. Selain karena suhu pengelasan, juga dipengaruhi oleh media pendingin atau heat-treatment yang 
digunakan. Untuk pengujian ini menggunakan media pendingin udara. Dengan adanya perubahan fisik butiran Si menjadi Si primer pada daerah las tersebut juga dimungkinkan terjadi perubahan sifat mekanik pada aluminium alloy 6061 untuk chasis gokart sebagai mana pada hasil dari uji impact.

Dengan demikian menyebabkan tingkat kekuatan pada daerah las lebih rapat dengan kampuh tirus tunggal, dan yang jarang kerapatannya di dapatkan dalam kampuh persegi (I tertutup).

\section{Kesimpulan}

1. Sifat mekanik Alumunium alloy 6061 variasi Kampuh dari hasil pengujian daerah Las, untuk chasis gokart nilai impak dan energi yang diserap rata-rata tertinggi diperoleh pada kampuh tirus tunggal arus 80 ampere yaitu $\mathrm{E}=119,819$ Joule dan $\mathrm{K}=1,198$ Joule $/ \mathrm{mm}^{2}$. sedangkan terendah diperoleh pada kampuh persegi (I tertutup) arus 80 ampere yaitu $\mathrm{E}=31,974$ Joule dan $\mathrm{K}=0,319$ Joule $/ \mathrm{mm}^{2}$.

2. Sifat mekanik Alumunium alloy 6061 variasi Kampuh dari hasil pengujian lengkung Bending, untuk chasis gokart nilai Bending dan energi yang diserap rata-rata tertinggi diperoleh pada kampuh tirus tunggal arus 80 ampere yaitu Fmax $=58,14 \mathrm{kgf}$ dan $\sigma=$ $570,353 \mathrm{Mpa}$. sedangkan terendah diperoleh pada kampuh persegi (I tertutup) arus 80 ampere yaitu Fmax $=24,53 \mathrm{kgf}$ dan $\quad \sigma=240,639 \mathrm{Mpa}$.

3. Bentuk struktur mikro pada Alumunium 6061 untuk chasis gokart dengan pengelasan TIG adalah Perlakuan preheat dan post heat menaikkan kelarutan magnesium dan silikon pada proses presipitasi, hal ini ditunjukkan dengan semakin larutnya atau berkurangnya formasi $\mathrm{Mg} 2 \mathrm{Si}$ pada hasil pengelasan dengan pemberian perlakuan preheat dan post heat. Juga berkurangnya porositas akibat difusi hidrogen untuk menghindari lemahnya sifat mekanik pada pengelasan TIG terhadap alumunium 6061 untuk chasiis gokart.

\section{Refrensi}

Teknologi Pengelasan logam / oleh Harsono Wiryosumarto, Toshie Okumura. Cet. 8 Jakarta: Pradnya Paramita, 2000

Halimatuddahliana. (2003). Pencegahan korosi dan scale pada proses produksi minyak bumi. USU digital library

Petunjuk Kerja Las / Oleh Sri Widharto. Cet. 6 - Jakarta : Pradnya Paramita, 2006

Sulardjaka,2005,Pengaruh Jenis Filler Pada Pengelasan Tig Transversal Butt Joint Terhadap Perilaku Retak Fatik Pada Pengelasan Paduan AL 6061 -T4, http//.www.yahoo onpdf.com

Pengantar untuk Memahami Proses Pengelasan Logam / Oleh Herry Sonawan, Rochim Suratman. Cet. 6 - Bandung CV Alfabeta 2006

Wiryosumarto, H, Okumurha T.,2004, Teknologi Pengelasan logam,cetakan ke-8 ,Pradnya Paramita, Jakarta.

Leonard Koellhoffer, August F. Manz, egene G. Hornberger. Welding Proscesses And Practices,III. Title, TS227.K59 671.5'2042 87-22981

ISBN 0-471-81671-X Printed In The United States Of America

Winarno, A, 2005,Studi Mutu Sambungan Las Oxyacetylene Dan Mig Pada Paduan http//.www.yahoo onpdf.com 
Widharto, 2006 Petunjuk Kerja Las Cet-6 - Jakarta: Pradnya Paramita

Sulardjaka,2005, Pengaruh Jenis Filler Pada Pengelasan Tig Transversal Butt Joint Terhadap Perilaku Retak Fatik Pada Pengelasan Paduan AL 6061 T4,http//.www.yahooonpdf.com

Awi Andoko1) Budi Harjanto2) Yuyun Estriyanto3) Analisa Struktur Hasil Repair Welding Tentang Sifat Fisik Dan Mekanik Pada Cast Wheel Aluminium Dengan Metode Pengelasan MIG

hhtp://www.mesin-teknik.blogspot.com.

http://www.en.wikipedia.org/wiki/Aluminium_alloy 